\title{
Experimental and numerical modal analysis of the first and second stage compressor blades
}

\author{
Seyed Mohammad Navid Ghoreishi ${ }^{a^{*}}$, Mohammad Salari ${ }^{b}$, Seyed Majid Pourhosseini ${ }^{\mathrm{c}}$ and Aram \\ Bahmanid $^{\text {d }}$
}

${ }^{a}$ Satellite Research Institute, Iranian Space Research Center, Tehran, Iran

${ }^{b}$ Faculty of Engineering, Department of Applied Mechanics, University of Qom, Qom, Iran

${ }^{c}$ Faculty of Mechanical Engineering, K.N. Toosi of Tech, Tehran, Iran

${ }^{d}$ Department of Mechanical and Mechateronics Engineering, University of Waterloo, Waterloo, Ontario, Canada

\begin{tabular}{l}
\hline A R T I C L EI N F O \\
\hline Article history: \\
Received 25 December, 2018 \\
Accepted 17 June 2019 \\
Available online \\
17 June 2019 \\
\hline Keywords: \\
Compressor blade \\
Modal analysis \\
Natural frequency \\
Numerical analysis \\
Experimental analysis
\end{tabular}

\begin{abstract}
A B S T R A C T
In this paper, the first and second stage compressor blades of a gas turbine were studied by the experimental and numerical modal analyses. At first, the geometric models of these blades were generated by the 3D scanner and then the mode shapes and the natural frequencies of each blade were extracted by a series of numerical modal analyses. The numerical results were compared with the data obtained from the experimental modal analysis and the validity and accuracy of the developed numerical models were confirmed. Unlike most studies that use fixed-free boundary condition for performing a modal analysis, this objective was pursued by applying a free-free boundary condition. This study also investigated the effect of using wax or glue for mounting the accelerometer on the blade by assessing the FRF curves obtained from the modal tests in the frequency range of $0-10000 \mathrm{~Hz}$. The sensitivity of the test results to applying free-free boundary condition, the number of accelerometers and their positions were investigated by defining three modal test configurations. The results obtained by these test configurations were compared with the results of numerical analyses and finally, the best configuration for the modal test of the studied compressor blade was determined.
\end{abstract}

\section{Introduction}

Blade failures could be caused by several mechanisms under the operating conditions of high rotational speed at elevated temperature. In general, blade failures could be classified into two categories: (a) fatigue, including both high cycle fatigue (HCF) and low cycle fatigue (LCF) (Burns, 1998; Sadowski \& Golewski, 2016; Shanyavskiy \& Toushentsov, 2016; Walls \& Cunningham, 1997) and (b) creep rupture (Hou et al., 1999; Persson \& Persson, 1993). The main failure mechanism in the compressor blades is the high cycle fatigue (HCF). Numerous reports of failure of the first stage compressor blades in frame-type gas turbines, such as at plants in China, Korea, USA and recently in Iran, show that similar fractures are due to compressor design errors. The modal analysis is a powerful tool for detecting and predicting fatigue failures in delicate components. The most important application of the modal analysis is detection of natural frequencies and mode shapes of the blades. Recognition of these natural frequencies can be useful to prevent the resonance effect and critical loads and resulting fatigue failures and shows internal defects such as notch, crack, void and etc. In the usual modal analysis of the blades,

\footnotetext{
* Corresponding author.

E-mail addresses: $\underline{\text { smn.ghoreishi@isrc.ac.ir }}$ (S. M. N. Ghoreishi)
} 
inspectors usually use a fixture to create fixed-free boundary conditions, but the time-consuming and costly procedure of designing a proper fixture makes this method non-optimal. In addition, the nonuniform or insufficient exertion of the support force upon the blade root can cause wobble, leading to reduced rigidity and inaccurate measurement. In contrast, applying excessive force is likely to cause damage and deformation in the blade root. Thus, attaining reliable and accurate results from this method requires high-precision design and implementation of boundary conditions.

So far, according to the importance of modal analyses of blades, several efforts have been made to evaluate the natural frequencies of blades (Bhat et al., 1996; Li et al., 2016; Marugabandhu \& Griffin, 2003; Sinha \& Turner, 2011; Wang et al., 2014; Yang et al., 2014). In this regard, Kim and Lee (2014) have studied modal characteristics and fatigue strength of compressor blades. They estimated the natural frequency of the first-, fifth-, and tenth-stage compressor blades, which varied in size and assembly method. These authors in another research (Kim \& Lee, 2013), have been studied modal characteristics according to the tip shape and assembly condition of the turbine blade. Effects of natural frequencies on the failure of R1 compressor blades have been discussed by Poursaeidi et al. (2012). They concluded that the resonance of the blades under the first and second natural frequency modes is the primary cause of the fatigue fractures of these blades. Vibration response analyses of a rotational shaft-disk-blade system with blade-tip rubbing have been studied by Ma et al. (2016). Choi and Lee (2010) have studied the failure of gas turbine blades. They observed that the fatigue fracture of the blade was originated during transient events internal to the combustion chamber which was close to the resonance condition of the assembled blades. In 2009, Witek (2009) examined the crack propagation in the helicopter turbo-engine compressor blades. He selected a number of extensively used but apparently healthy compressor blades (healthy in terms of presence of cracks and holes) and subjected them to their first mode of transverse natural vibration, examining the resulting crack propagation rate. In the second part of this research, he used a nonlinear finite element method to obtain the stress distribution during vibration and ultimately reported that the maximum principal stress is located in the zone where the crack begins.

Different articles that have used numerical analyses to study the compressor blades have pursued this objective through a wide variety of techniques, meshes, and modeling elements. In this regard, Hou et al. (2002), who combined the finite element method with an experimental approach to study the effect of blade root flexibility on the vibration characteristics of the gas turbine blades, used tetrahedral elements due to geometrical complexity of the assessed blade. In the study conducted by Markowski et al. (2011), which they modeled and analyzed the free vibrations of a gas turbine blade, authors meshed most part of the model by "hex type" elements but completed the remaining parts by a combination of "wedge" and "tetrahedral" elements. Assef and Mahfuz (2009) used sweep meshing technique by hex and wedge elements in the ANSYS software to model and analyze the turbine blades. All these works indicate that the type of element to be used must be selected based on the blade geometry and its complexity. Although regular hex elements provide excellent precision and speed for FE analysis, the complexity of blade geometry usually necessitates the use of tetrahedral elements implemented via a free meshing technique to generate the model.

In this study, the natural frequencies of gas turbine blades were estimated by using a free-free boundary condition in place of fixed-free condition used in conventional modal analyses. The free-free boundary condition for the modal test can simplify the process of implementing boundary condition and enhance the accuracy of modal analysis. The review of related works shows that most studies on this subject first develop a simple geometric model, and then apply the results of the modal analysis to modify it such that its results get sufficiently close to the experimental data. In the present study, the 3D scanned models were employed to eliminate the process of trial and error normally needed to update and modify the numerical model. This approach gives a direct high-precision technique in modeling. Also, a series of modal tests were performed to validate the numerical model obtained for the first and second stage of compressor blades. In addition, the effect of using glue and wax for mounting the accelerometers on the blade was assessed, as these are the most common materials used in experimental modal tests for this 
purpose. To detect the cause of slight differences between the experimental and numerical results in some vibration modes, the experimental modal tests with three different test configurations were repeated to assess the sensitivity of results to boundary condition and the number and location of the accelerometers.

\section{Numerical modal analysis of the first and second stage compressor blades}

For modal and harmonic finite element analyses, the geometric model of each blade was created. These models were obtained by converting the cloud points of the blades collected by a 3D-scanning device to the resulting 3D models using the CATIA software. As mentioned, this method provides an accurate and realistic model and eliminates the updating procedure of alternative numerical approaches. Thereafter, the ABAQUS software was used to perform a modal numerical analysis on the first and second stage blades. In these numerical analyses, a hex-dominant mesh with 8 nodes was used to model the first stage blades and a Tet-dominant mesh with 10 nodes was used for the second stage blades. These analyses were based on the assumptions of the free-free boundary condition. The material properties of the FE models are listed in Table 1.

Table 1. Material properties for numerical modeling of the blades

\begin{tabular}{cccc}
\hline Quantity & Value & Quantity & Value \\
\hline Material & Titanium & Young's modulus & $118 \mathrm{GPa}$ \\
Density & $4510 \mathrm{~kg} / \mathrm{m} 3$ & Poisson's ratio & 0.36 \\
\hline
\end{tabular}

\subsection{Modal analysis}

After omitting the rigid modes, the first three natural frequencies and mode shapes obtained for the first stage blade are shown in Figs. 1 to 3.

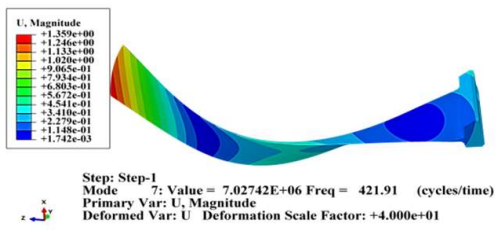

Fig. 1. The first mode shape of the first stage blade

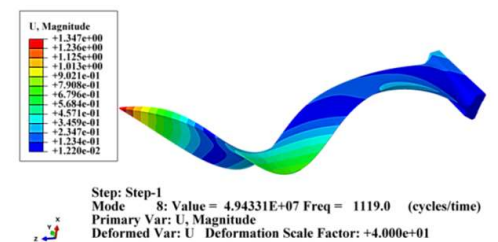

Fig. 2. The second mode shape of the first stage blade

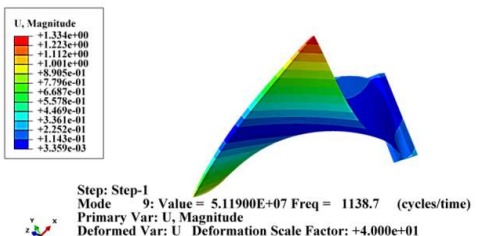

Fig. 3. The third mode shape of the first stage blade

The first and second modes are the first and second bending modes and the third mode is the first torsional mode. Three first modes are important because of two reasons. The first reason is the amplitude of natural frequency after the third mode is much higher than the working frequency of the blade and the second reason is related to the tip displacement of the blade which is too low after the third mode. The dynamic numerical analysis of the first stage blade was performed in the frequency range of 250 to 1250 Hz. In this analysis, the three points shown in Fig. 4 were subjected to a transverse sinusoidal force of 5 $\mathrm{N}$ applied with varying frequency (within the mentioned frequency range) along $\mathrm{X}$-axis. The obtained frequency response function (FRF) curves are shown in Fig. 5.

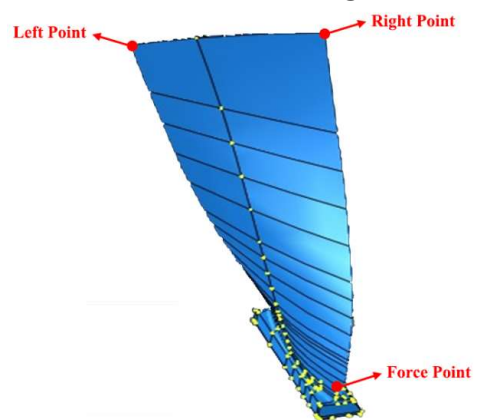

Fig. 4. The points of application of the sinusoidal force. 


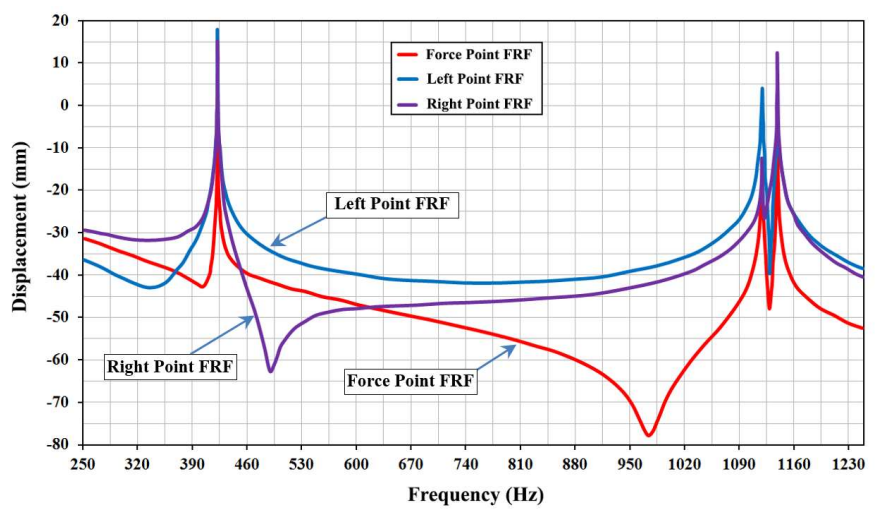

Fig. 5. The FRF curves of the three points defined on the first stage blade.

\subsection{Model verification}

To assess the sensitivity of the results to the type of the mesh element and verify the FEA model, ABAQUS and COMSOL software were used to conduct a series of numerical modal analyses with triangle meshes. The results of all numerical analyses are shown in Table 2. As Table 2 shows, the results of the modal and harmonic analysis, both conducted with structural meshing on the first stage blade are very close to each other and have an error of less than $0.1 \%$, which points to the validity of these analyses. Natural frequencies obtained by the modal analysis with structural meshing have 1 to $2 \%$ difference with those obtained by free meshing. The difference between the results of the modal analyses conducted in ABAQUS and COMSOL is less than $0.5 \%$, reflecting the accuracy of the performed numerical analyses.

Table 2. Numerical results of the natural frequencies for the first stage blade

\begin{tabular}{cccc}
\hline Type of analysis & $\begin{array}{c}\text { First natural } \\
\text { frequency (Hz) }\end{array}$ & $\begin{array}{c}\text { Second natural } \\
\text { frequency (Hz) }\end{array}$ & $\begin{array}{c}\text { Third natural } \\
\text { frequency (Hz) }\end{array}$ \\
\hline Modal analysis with structural meshing (ABAQUS) & 421.91 & 1119 & 1138.7 \\
Modal analysis with free meshing (ABAQUS) & 429.25 & 1128.3 & 1143.1 \\
Harmonic analysis with structural meshing (ABAQUS) & 422 & 1118 & 1139 \\
Modal analysis with free meshing (COMSOL) & 429.32 & 1128.43 & 1143.34 \\
\hline
\end{tabular}

All numerical modal analyses conducted on the model of the first stage blade were also repeated on the geometric model developed for the second stage blades. Three different second stage blades were used for analyses. These blades are named with the codes listed in Table 3 and will be hereafter referred to by those names.

Table 3. The codes of the second stage blades were used for analyses

\begin{tabular}{cc}
\hline Blade number & Code of blade \\
\hline 1 & ST\#2-01 \\
2 & ST\#2-02 \\
3 & ST\#2-03 \\
\hline
\end{tabular}

For example, the first mode shape of the blade ST\#2-02 is shown in Fig. 6. As Fig. 6 shows, this mode is transversal and its first natural frequency is $531.28 \mathrm{~Hz}$.

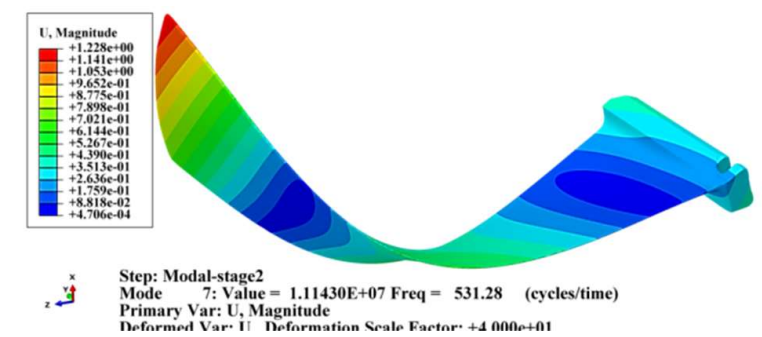

Fig. 6. The first mode shape of blade ST\# 2-02. 


\section{Experimental modal analysis of the first and second stage compressor blades}

The experimental modal analyses were performed to determine the modal characteristics of the system. These analyses were used to extract and report the first three natural frequencies of the first stage blade. Comparing the results of the modal test with those of numerical analyses can demonstrate the accuracy of the numerical model and provide the necessary basis for investigating other operational factors such as mechanical and thermal shock, heat transfer, forced vibrations and etc. Also, the modal analysis method will be modified and validated according to FEM results. This procedure will be cost effective and reduces fixture design and fabrication costs.

All tests to be described here were based on free-free boundary conditions. In all these tests, an impact hammer was used to make an input and the resulting outputs were recorded by the accelerometers mounted on the blade. The results of the modal tests were converted to frequency response function (FRF) curves to facilitate the investigations. In the test performed on the first stage blade, the desired inputs were applied by a B\&K 8202 modal hammer on the blade that was suspended by an elastic string to emulate free-free boundary condition (Fig. 7).

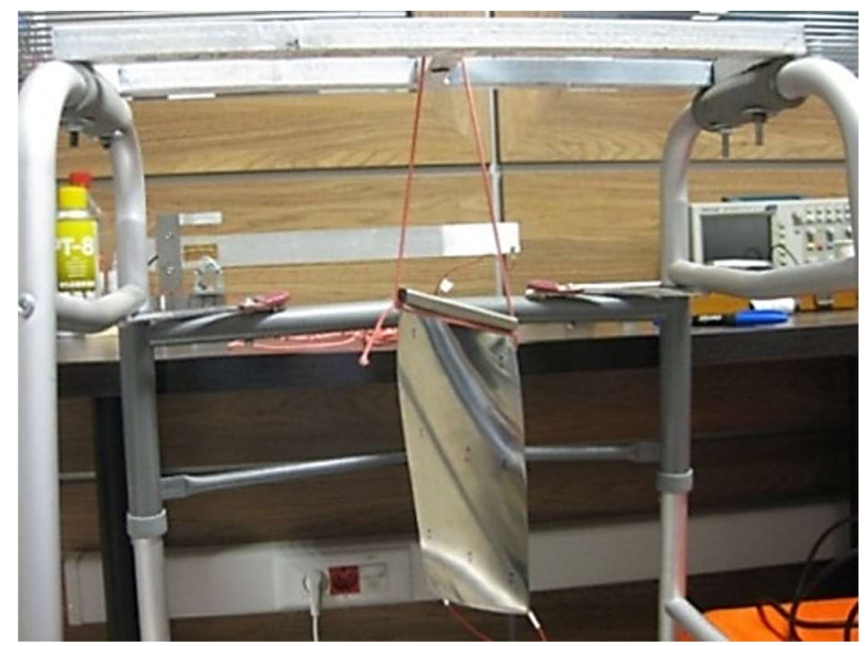

Fig. 7. The free-free boundary condition emulated by suspending the blade by an elastic string

The schematic pattern for the location of applied force and accelerometers mounted on the first stage blade is shown in Fig. 8. As Fig. 8 shows, the force was applied to the points 1 to 8, and then two miniature piezoelectric accelerometers Endevco ${ }^{\circledR}$ model 2222C were used to record the outputs at the points Accel 1 and Accel 2 that located at the tip of the blade. The process of applying force on each point was repeated 10 times and the recorded responses were averaged to obtain the final output. In these tests, the module Endevco ${ }^{\circledR}$ model 133 was used as a vibrating signal conditioner and the module NI4431 was used for dynamic signal acquisition.

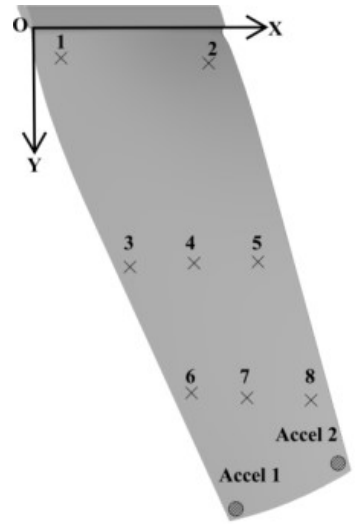

Fig. 8. The schematic pattern for location of the applied force and accelerometers mounted on the first stage blade 
Fig. 9 shows the FRF curves pertaining to two points defined on the first stage blade. As mentioned, these curves were obtained from the modal test conducted with free-free boundary condition. According to this plot, the first three natural frequencies of the first stage blade are $426 \mathrm{~Hz}, 1053 \mathrm{~Hz}$, and $1142 \mathrm{~Hz}$ in that order. These curves clearly show that the second and third non-rigid natural frequencies of the first stage blade are very close (have a difference of less than $90 \mathrm{~Hz}$ ) and this greatly increases the possibility of resonance in that particular range.

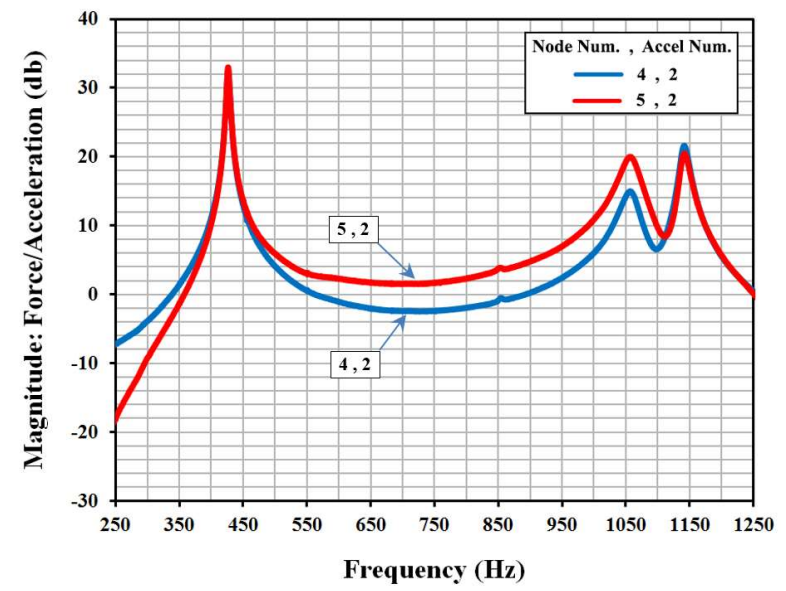

Fig. 9. FRF curves of the first stage blade

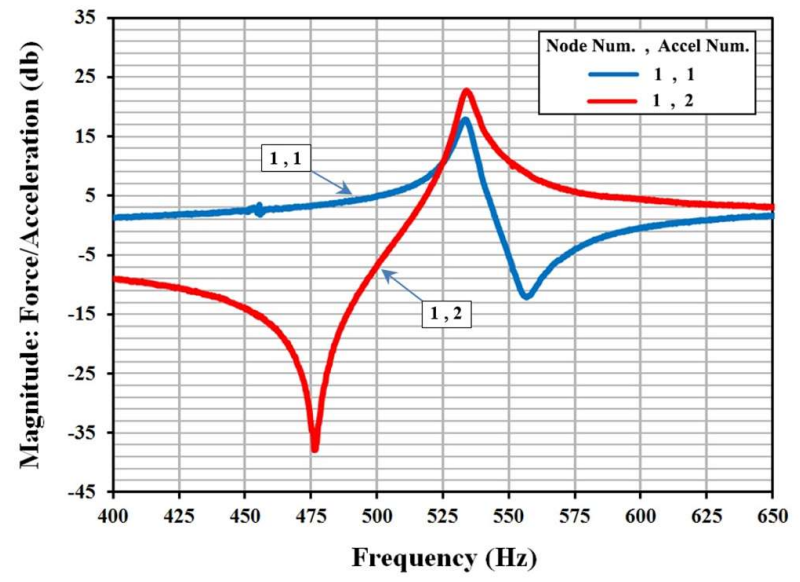

Fig. 10. FRF plot of the blade ST\#2-01

The test method of the second blade is exactly like the first blade. Fig. 10 shows the FRF curves pertaining to the blade ST\#2-01. The first natural frequency of this blade is $533 \mathrm{~Hz}$. In this group of test, there were 7 points of impact and 2 points of signal acquisition, producing a total of 14 FRF curves, of which only two are plotted in Fig. 10 to avoid confusion. In this test, accelerometers were mounted on the blade by the glue.

\subsection{The effect of the materials used to mount the accelerometer}

Proper mounting of the accelerometers on the test piece is one of the important steps of the modal test, as it can affect the accuracy of the results. There are several ways to mount the accelerometer (Ancimer and Cheung, 2008, Christensen Jr, 1989, Stoddard and Smith, 1998), including the use of glue, wax, magnet, or screws. The mass of accelerometer is an important parameter of the test, so researchers often use glue or wax to mount miniature accelerometers on the system. In the remainder of this section, the results of modal tests were obtained by using wax and glue to mount the accelerometer. The results of the tests were conducted on the blade ST\#2-03 in two scenarios of using glue and wax to mount the accelerometers, are shown in Fig. 11. In this figure, the light and dark blue FRF curves represent the results of point 3 in glue scenario and the light and dark red FRF curves represent the results of point 2 in wax scenario; but these are only some examples of results obtained for 7 points and 10 impacts of each scenario and are illustrated in this brief form to avoid confusion. According to this figure, the modal test conducted by wax is not suitable for frequencies above $4000 \mathrm{~Hz}$, because the peaks of natural frequencies are omitted by damping effect. It is also clear that FRF curves of wax scenario (red curves) have smoother peaks (because of damping) which make the natural frequencies more difficult to detect. Also, after the first two natural frequencies, the red curves, which represent the results of wax scenario, are slightly smoother than the blue curves representing the glue scenario. This smoothness is due to the slight increase in mass of the system caused by the use of wax. This effect is clearly recognizable at frequencies higher than $2000 \mathrm{~Hz}$. The blue curves, which represent the results of glue scenario, exhibit continuous turbulences in frequencies higher than $3500 \mathrm{~Hz}$, but in the wax scenario, this phenomenon appears after the frequency of $7200 \mathrm{~Hz}$. Therefore, the use of wax for mounting the accelerometer on the blade should 
be restricted to the tests conducted on frequency ranges of less than $2000 \mathrm{~Hz}$; otherwise the obtained results will be far less accurate than the results obtainable by using the glue.

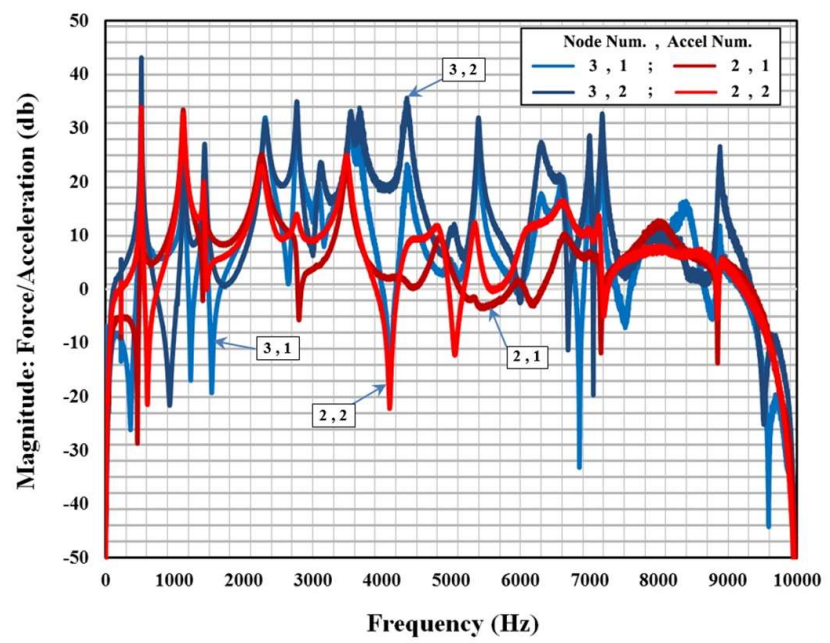

Fig. 11. FRF curves of the blade ST\#2-03 obtained by using wax and glue for mounting the accelerometer

Table 4 shows the first two natural frequencies of the blade ST\#2-03 for wax and glue test scenarios. The purpose of these tests was to investigate the effect of conducting the modal tests by the use of wax instead of glue. Although using the wax instead of glue simplifies the process of mounting and dismounting the accelerometers, the first and second natural frequencies of the blades in the wax scenario are $0.38 \%$ and $1.75 \%$ lower than the frequencies observed in the glue scenario; a difference that can be attributed to the damping effect of the wax and the slightly larger mass imposed to the system by using the wax instead of glue. The important result is that glue is better than wax and mechanical connection method.

Table 4. The first two natural frequencies of the blade ST\#2-03 for wax and glue test scenarios

\begin{tabular}{cccc}
\hline Natural frequency $(\mathrm{Hz})$ & Modal test with glue & Modal test with wax & Deference $(\%)$ \\
\hline First & 520 & 518 & 0.38 \\
Second & 1146 & 1126 & 1.75 \\
\hline
\end{tabular}

\subsection{The effects of boundary condition, location and number of accelerometers on the test results}

The effect of boundary condition and accelerometers status on the test results was examined by defining three different test configurations and repeating the modal tests of the first stage blade with these test setups. Table 5 describes the three defined modal test configurations.

Table 5. Three configurations of the modal tests

\begin{tabular}{|c|c|}
\hline Configuration & Descriptions \\
\hline First & $\begin{array}{l}\text { The } 1.6 \text { meters long elastic string attached to the root of the blade, An accelerometer } \\
\text { attached to the tip of the blade with glue }\end{array}$ \\
\hline Second & $\begin{array}{l}\text { The } 1.6 \text { meters long elastic string attached to the center of the blade, An } \\
\text { accelerometer attached to the tip of the blade with glue }\end{array}$ \\
\hline Third & $\begin{array}{l}\text { The } 1.6 \text { meters long elastic string attached to the center of the blade, An } \\
\text { accelerometer attached to the center of the blade with glue }\end{array}$ \\
\hline
\end{tabular}

As Table 5 presents, in this group of tests, the 0.3 -meter long elastic string used in previous tests was replaced with a longer 1.6-meter string to reduce the effect of fixed boundary condition and make the simulation as close as possible to free-free boundary condition. The first and second test configurations had similar numbers and arrangement of accelerometers and their difference was at the point at which blade was attached to the elastic string. This enabled engineers to determine the effect of changes in the 
boundary conditions on the results of the modal test. The only difference between the second and the third test configurations was in the points at which accelerometers were mounted. The purpose of the third test configuration was to assess the dependence of modal test results on the location of accelerometers. The schematic pattern for the location of the applied force and accelerometers for the first stage blade is shown in Fig. 12. As Fig. 12 shows, in this group of tests, the impact was applied to two points 1 and 2 located on the first stage blade and the output was recorded by an accelerometer mounted at the point Accel 1 or Accel 2 (depending on the test configuration).

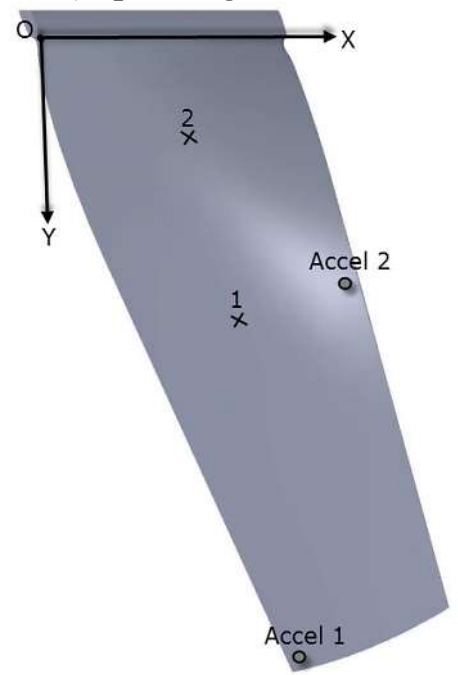

Fig. 12. The schematic pattern for location of the applied force and accelerometers on the first stage blade

Table 6 represents the first three natural frequencies obtained from the modal test conducted on the first stage blade. According to this table, the natural frequencies obtained by the first and second test configurations are generally the same (the only difference is that the second natural frequency obtained in the second test configuration is $1 \mathrm{~Hz}$ higher than that in the first test configuration), so it can be concluded that the method of applying free-free boundary condition, i.e. the length of elastic string and the location of string attachment, have not any impact on the results of the modal test.

Table 6. The results of natural frequency test for 3 configurations of the first stage blade

\begin{tabular}{cccc}
\hline Configuration & First natural frequency $(\mathrm{Hz})$ & Second natural frequency $(\mathrm{Hz})$ & Third natural frequency $(\mathrm{Hz})$ \\
\hline First & 433 & 1118 & 1170 \\
Second & 433 & 1119 & 1170 \\
Third & 438 & 1157 & 1177 \\
\hline
\end{tabular}

The first three natural frequencies of the third test configuration are all higher than those obtained in the second test configuration. The only difference between the second and third test configurations was that the accelerometer was moved from the tip of the blade toward the center. As a result of this change, all natural frequencies have been altered, especially the second one which has increased by $3.39 \%$. This higher increase of second natural frequency compared to other frequencies is due to the torsional nature of this mode. In the third configuration, the accelerometer is mounted close to the node of torsion mode and the concentrated mass from the blade tip, which undergoes the greatest deformation in the torsion mode, is closed to the node. As a result, the mass has a lower effect on this mode than others, which explains the greater increase in the natural frequency of this mode as compared to the others. This shows that the results of the modal test conducted on the blade depend on the mass of the accelerometer and the location where it is mounted. The same conclusion can be reached via a different aspect of analysis. Comparison of the results obtained by the initial modal test $(0.3 \mathrm{~m}$ long elastic string attached to the blade root and two accelerometers mounted on the tip) and results of the modal test conducted with the first configuration (1.6 m long elastic string attached to the blade root and only one accelerometer mounted on the tip) shows that a reduction in the number of accelerometers has led to a significant increase in the 
natural frequencies of the blade (Table 7). This increase is due to a reduction of mass caused by using a lower number of accelerometers for testing the system.

Table 7. The results of the natural frequency test for two different configurations of the first stage blade

\begin{tabular}{cccc} 
Configuration & First natural frequency $(\mathrm{Hz})$ & Second natural frequency $(\mathrm{Hz})$ & Third natural frequency $(\mathrm{Hz})$ \\
\hline Initial configuration & 426 & 1053 & 1143 \\
$\begin{array}{c}\text { First configuration } \\
\text { (described in Table 5) }\end{array}$ & 433 & 1118 & 1170 \\
Increase rate (\%) & 1.64 & 6.17 & 2.36 \\
\hline
\end{tabular}

Table 8 compares the results obtained from numerical and experimental analyses. As Table 8 shows, mounting two accelerometers at the tip of the blade causes the first and third natural frequencies obtained by the modal test to have excellent agreement (less than $1 \%$ difference) with the results of numerical analyses; however there is an approximately $6 \%$ difference between experimental and numerical results pertaining to the second natural frequency, which can be reduced by using the second test configuration (where only one accelerometer gets mounted on the tip of the blade). However, this test configuration leads to $2.5 \%$ difference in the experimental and numerical results of the first and third natural frequencies. Using the third configuration has led to $3 \%$ to $4 \%$ difference between numerical and experimental results of all natural frequencies, so given the uniformity of these differences, this test configuration provides more reliable responses than the others.

Table 8. The results of natural frequency test for 3 configurations of the first stage blade

\begin{tabular}{|c|c|c|c|c|c|}
\hline \multicolumn{2}{|c|}{ Type of analysis } & Blade stage & $\begin{array}{c}\text { First natural } \\
\text { frequency }(\mathrm{Hz})\end{array}$ & $\begin{array}{l}\text { Second natural } \\
\text { frequency }(\mathrm{Hz})\end{array}$ & $\begin{array}{c}\text { Third natural } \\
\text { frequency }(\mathrm{Hz})\end{array}$ \\
\hline \multirow{2}{*}{\multicolumn{2}{|c|}{ Numerical }} & First stage & 422 & 1118 & 1139 \\
\hline & & ST\#2-02 & 531 & - & - \\
\hline \multirow{7}{*}{ Experimental } & \multirow{4}{*}{ Initial configuration } & First stage & 426 & 1053 & 1142 \\
\hline & & ST\#2-01 & 520 & - & - \\
\hline & & $\mathrm{ST} \# 2-02$ & 533 & - & - \\
\hline & & ST\#2-03 & 520 & - & - \\
\hline & \multirow{3}{*}{$\begin{array}{l}\text { First configuration } \\
\text { Second configuration } \\
\text { Third configuration }\end{array}$} & First stage & 433 & 1118 & 1170 \\
\hline & & First stage & 433 & 1119 & 1170 \\
\hline & & First stage & 438 & 1157 & 1177 \\
\hline \multirow{5}{*}{$\begin{array}{l}\text { Difference between } \\
\text { numerical and } \\
\text { experimental results }(\%)\end{array}$} & \multirow{2}{*}{ Initial configuration } & First stage & 0.94 & 6.17 & 0.26 \\
\hline & & ST\#2-02 & 0.38 & - & - \\
\hline & \multirow{3}{*}{$\begin{array}{l}\text { First configuration } \\
\text { Second configuration } \\
\text { Third configuration }\end{array}$} & First stage & 2.54 & 0.00 & 2.65 \\
\hline & & First stage & 2.54 & 0.09 & 2.65 \\
\hline & & First stage & 3.65 & 3.37 & 3.23 \\
\hline
\end{tabular}

\section{Design of fixture for first stage blade}

After verification of modal test and determination test method and accelerometer location, a fixture is designed to simulate real boundary condition of blade. In this regards, first of all a FEM model will be used to verify boundary condition and then a fixture will be manufactured and experimental modal test will be performed.

\subsection{Finite element analysis of blade and fixture}

For modeling and analyzing of interaction effect on modal result, a fixture like Fig. 13 was design and developed in ABAQUS software. Boundary condition in this model is friction between root blade and fixture and a preload which is imposed by a screw. This screw tries to spread uniform load on root. 


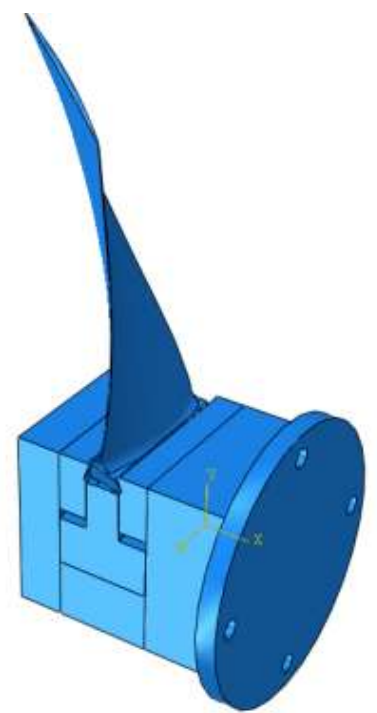

Fig. 13. First stage blade and designed fixture in ABAQUS software

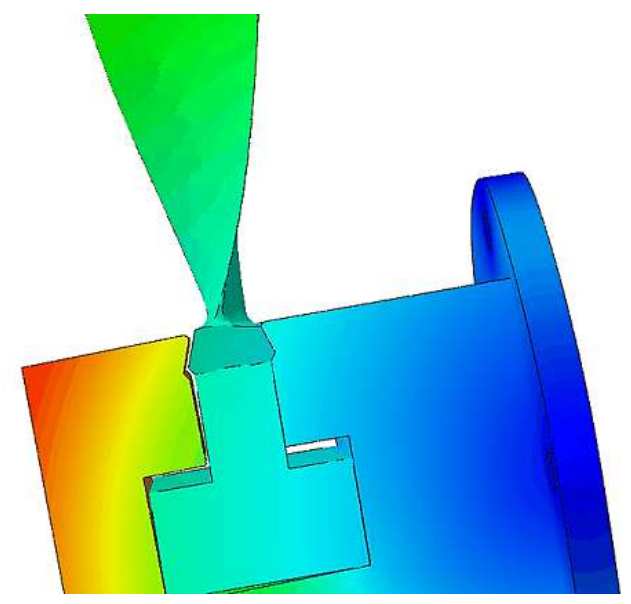

Fig. 14. Modal analyzing of designed fixture and first stage blade

Modal analyzing of designed fixture and first stage blade has been shown in Fig. 14. This figure shows inaccurate boundary condition on root blade. Based on FEM results, for modeling accurate boundary condition on root blade, some modifications on fixture have been done and fixture was optimized and designed like Fig. 15. Two holes were improvised in body and little change was done on fillet and bread fixture. The final manufactured fixture has been shown in Fig. 16. The fixture material was CK45. Black oxidant was used as final surface procedure.

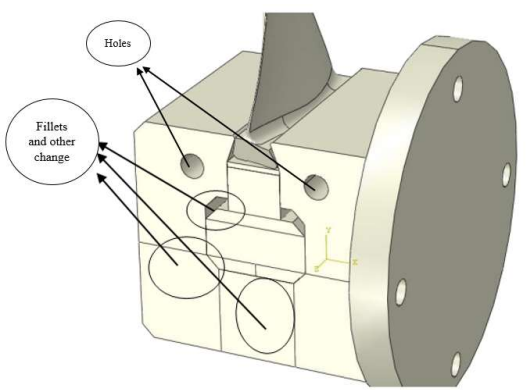

Fig. 15. Optimized fixture

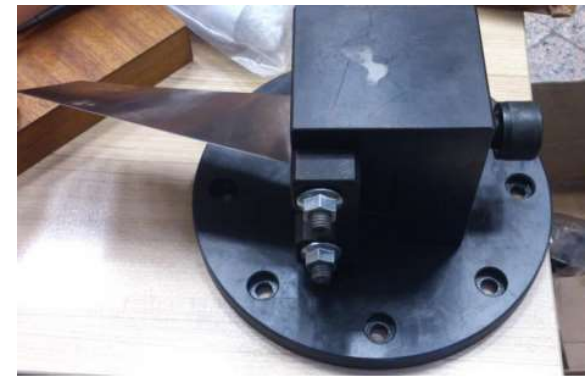

Fig. 16. Final manufactured fixture

The first three natural frequencies and mode shapes obtained for the first stage blade and fixture are shown in Figs. 17 to 19.

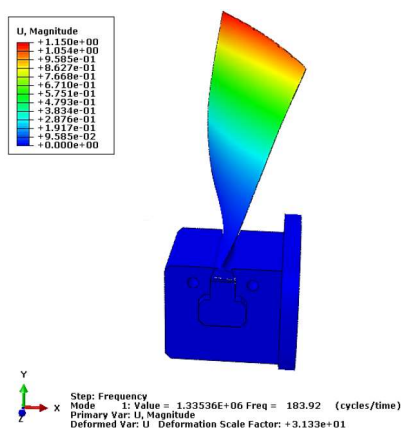

Fig. 17. The first mode shape of the first stage blade and fixture

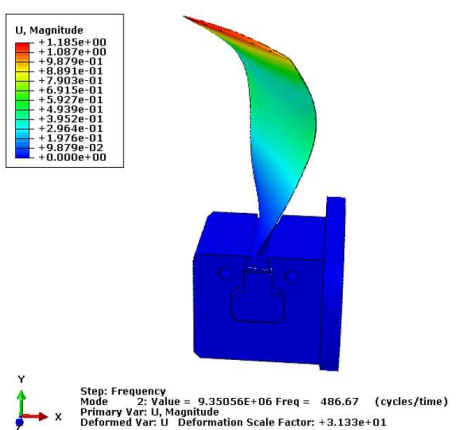

Fig. 18. The second mode shape of the first stage blade and fixture

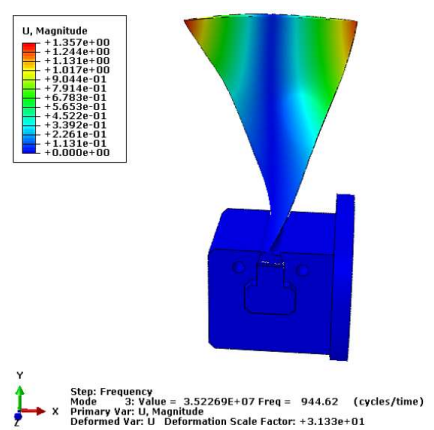

Fig. 19. The third mode shape of the first stage blade and fixture 


\subsection{Experimental modal tests of blade and fixture}

Experimental modal tests for blade and fixture have been done with shaker excitation and sensing data with accelerometer and laser. A shaker type of LDS V830-335 from B\&K Company, accelerometer type of Dytran 3056B2 and laser type of optoNCDT 2300 have been used for these experimental tests. Arrangement of experimental modal test for blade and fixture has been shown in Fig. 20.

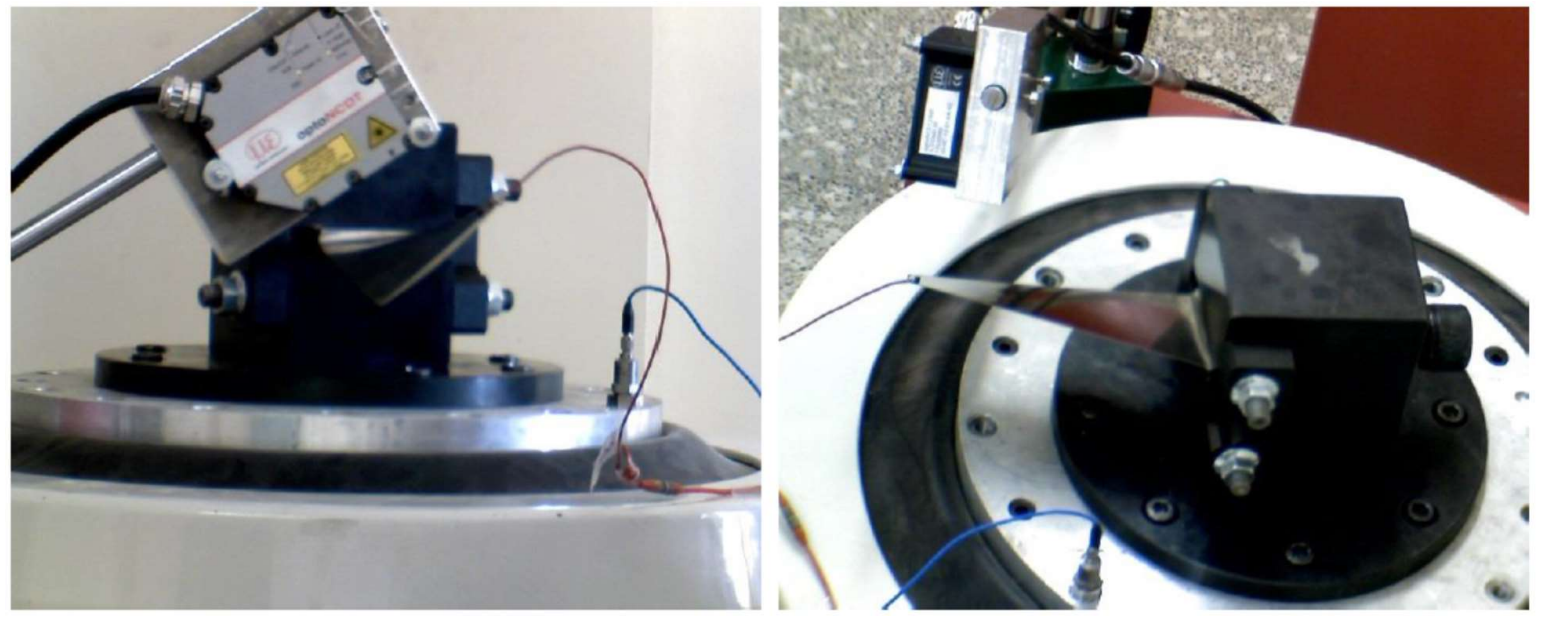

Fig. 20. Arrangement of experimental modal test for blade and fixture.

The Results of tests conducted on the blade ST\#1-01 in two scenarios of using accelerometer and laser to sensing data are shown in Figures 21 and 22, respectively. According to these figures, it is revealed that, results of using accelerometer and laser for data sensing, are close to each other and the first, second and third natural frequencies of blade and fixture are 187, 488 and 917 respectively.

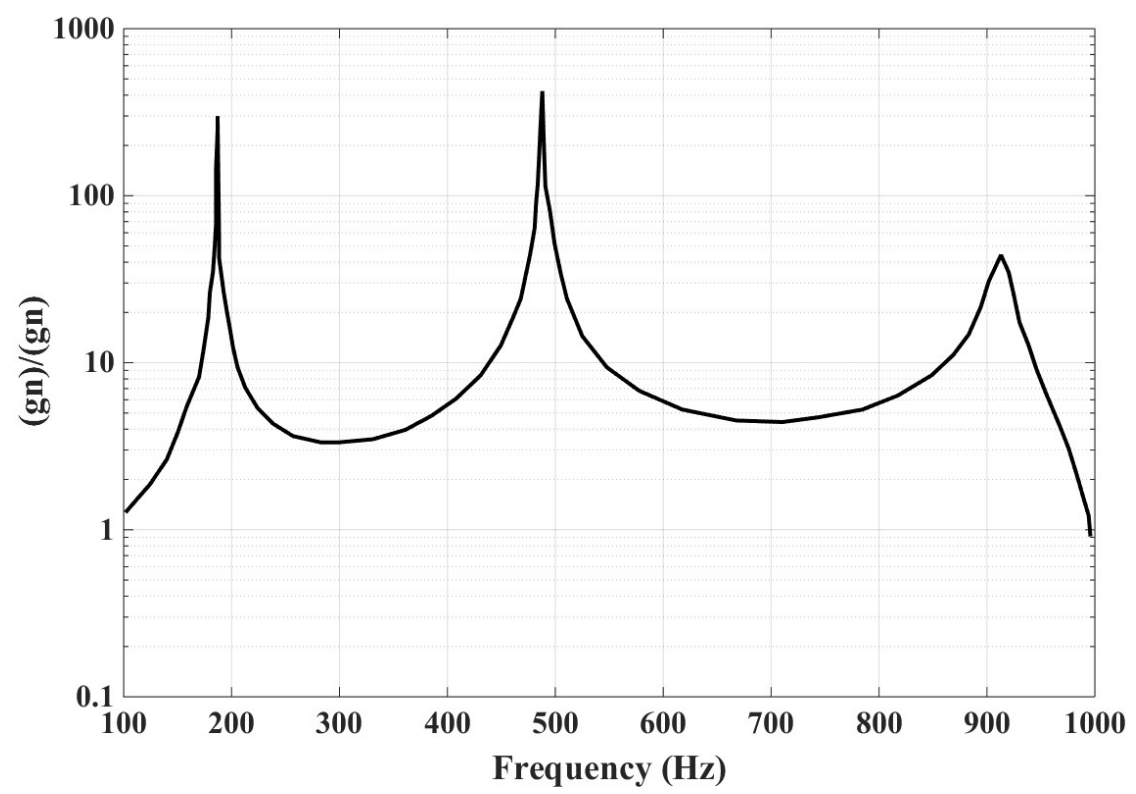

Fig. 21. FRF curves of the fixture and blade ST\#1-01 obtained by using the accelerometer. 


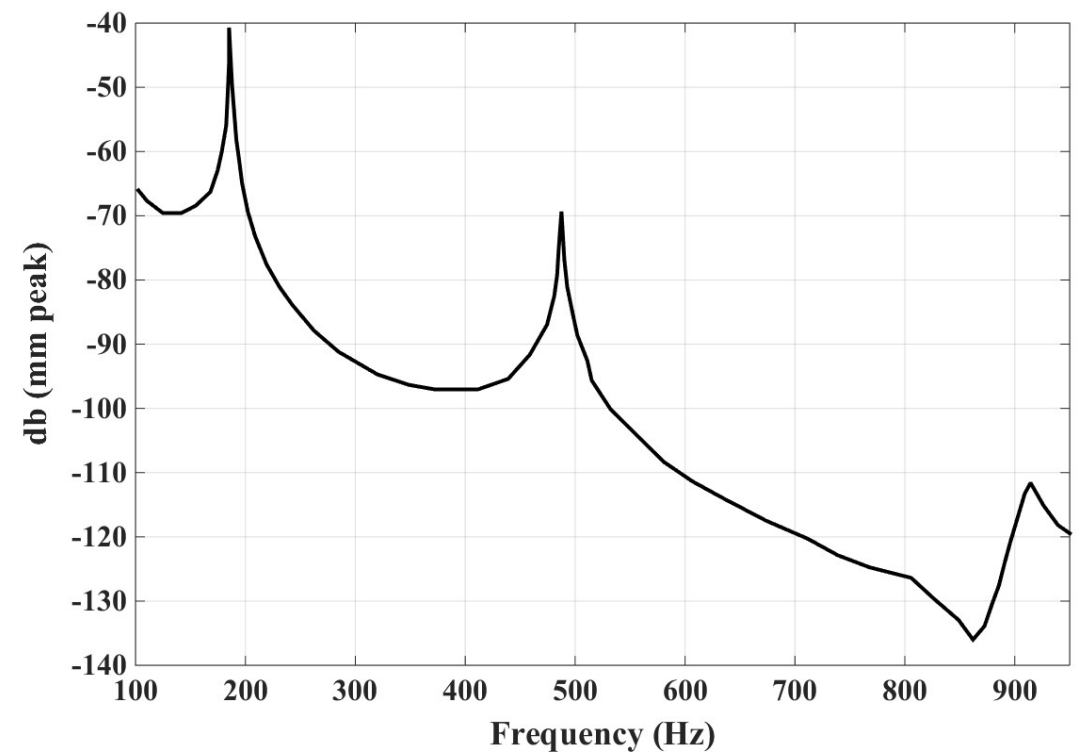

Fig. 22. FRF curves of the fixture and blade ST\#1-01 obtained by using the laser.

Comparing experimental results with FEM show that FEM results are to close with experimental test and errors are less than 3 present. Therefore, using FEM methods have a good accuracy in the modal analyzing of blade and fixture. Thus, these numerical methods could be replaced with expensive and time consuming experimental tests for modal analyzing of blade and fixture.

\section{Conclusions}

In this paper, the first and second stage compressor blades of a gas turbine were studied by numerical and experimental modal analyses. Three test configurations were defined to calculate the sensitivity of the test results to boundary condition type, the number of accelerometers and the location where they are mounted. This observation originates from the mass variation caused by using a different number of accelerometers and the change in the moment of inertia caused by moving the accelerometers location. Based on the analysis above, the following conclusions can be obtained:

- This group of tests showed that the manner of applying free-free boundary condition (the length of the elastic string and the point at which blade is attached to the string) have no impact on the results of the modal tests.

- Changing the number and location of accelerometers made significant changes in the obtained results.

- Only one accelerometer mounted on the center of the blade, produces the most reliable results.

- Use of wax instead of glue should be restricted to those modal tests that investigate the frequencies of less than $2000 \mathrm{~Hz}$.

- FEM has a good accuracy in the modal analysis of the blade. Therefore, the numerical analysis could be replaced with the expensive and time-consuming experimental modal analysis.

\section{References}

Ancimer, R., \& Cheung, D. (2008). U.S. Patent No. 7,444,231. Washington, DC: U.S. Patent and Trademark Office.

Asseff, N. S., \& Mahfuz, H. (2009). Design and finite element analysis of an ocean current turbine blade (pp. 1-6). IEEE.

Bhat, M. M., Ramamurti, V., \& Sujatha, C. (1996). Studies on the determination of natural frequencies of industrial turbine blades. Journal of Sound and Vibration, 196(5), 681-703. 
Burns, J. (1998). Gas turbine engine blade life prediction for high cycle fatigue. The Technical Cooperation Program (TTCP), P-TP1.

Choi, Y. S., \& Lee, K. H. (2010). Investigation of blade failure in a gas turbine. Journal of Mechanical Science and Technology, 24(10), 1969-1974.

Christensen Jr, A. B. (1989). U.S. Patent No. 4,823,602. Washington, DC: U.S. Patent and Trademark Office.

Hou, J., Wicks, B. J., Stocks, G. J., Slater, S. L., \& Antoniou, R. A. (1999). Creep failure assessment of a turbine disc using non-linear finite element method. In IS-121, 24th ISABE Conference Proceedings.

Hou, J., \& Wicks, B. J. (2002). Root flexibility and untwist effects on vibration characteristics of a gas turbine blade (No. DSTO-RR-0250). DEFENCE SCIENCE AND TECHNOLOGY ORGANIZATION VICTORIA (AUSTRALIA) PLATFORM SCIENCES LAB.

Kim, K., \& Lee, Y. S. (2014). Modal characteristics and fatigue strength of compressor blades. Journal of Mechanical Science and Technology, 28(4), 1421-1429.

Kim, K. K., \& Lee, Y. S. (2013). Modal characteristics according to the tip shape and assembly condition of the turbine blade. Journal of Mechanical Science and Technology, 27(11), 3409-3417.

Li, L., Li, Y. H., Liu, Q. K., \& Jiang, B. K. (2016). Effect of balance weight on dynamic characteristics of a rotating wind turbine blade. Journal of Engineering Mathematics, 97(1), 49-65.

Ma, H., Lu, Y., Wu, Z., Tai, X., \& Wen, B. (2016). Vibration response analysis of a rotational shaftdisk-blade system with blade-tip rubbing. International Journal of Mechanical Sciences, 107, 110125 .

Markowski, T., Noga, S., \& Rudy, S. (2011). Modelling and vibration analysis of some complex mechanical systems. In Recent Advances in Vibrations Analysis. IntechOpen.

Marugabandhu, P., \& Griffin, J. H. (2003). A reduced-order model for evaluating the effect of rotational speed on the natural frequencies and mode shapes of blades. Journal of Engineering for Gas Turbines and Power, 125(3), 772-776.

Persson, C., \& Persson, P. O. (1993). Evaluation of service-induced damage and restoration of cast turbine blades. Journal of Materials Engineering and Performance, 2(4), 565-569.

Poursaeidi, E., Babaei, A., Arhani, M. M., \& Arablu, M. (2012). Effects of natural frequencies on the failure of R1 compressor blades. Engineering Failure Analysis, 25, 304-315.

Sadowski, T., \& Golewski, P. (2016). Cracks path growth in turbine blades with TBC under thermomechanical cyclic loadings. Frattura ed Integrità Strutturale, 10(35), 492-499.

Shanyavskiy, A., \& Toushentsov, A. (2016). Multiaxial fatigue of in-service aluminium longerons for helicopter rotor-blades. Frattura ed Integrità Strutturale, 10(37), 22-27.

Sinha, S. K., \& Turner, K. E. (2011). Natural frequencies of a pre-twisted blade in a centrifugal force field. Journal of Sound and Vibration, 330(11), 2655-2681.

Stoddard, D. R., \& Smith, D. G. (1998). U.S. Patent No. 5,723,787. Washington, DC: U.S. Patent and Trademark Office.

Walls, D. P., deLaneuville, R. E., \& Cunningham, S. E. (1995, June). Damage tolerance based life prediction in gas turbine engine blades under vibratory high cycle fatigue. In ASME 1995 International Gas Turbine and Aeroengine Congress and Exposition (pp. V005T14A020-V005T14A020). American Society of Mechanical Engineers.

Wang, Z., Wang, Z., Zhuang, L., \& Wang, A. N. (2014). Time-dependent vibration frequency reliability analysis of blade vibration of compressor wheel of turbocharger for vehicle application. Chinese Journal of Mechanical Engineering, 27(1), 205-210.

Witek, L. (2009). Experimental crack propagation and failure analysis of the first stage compressor blade subjected to vibration. Engineering Failure Analysis, 16(7), 2163-2170.

Yang, J., Yuan, S., Yuan, J., Si, Q., \& Pei, J. (2014). Numerical and experimental study on flow-induced noise at blade-passing frequency in centrifugal pumps. Chinese Journal of Mechanical Engineering, 27(3), 606-614. 
(C) 2019 by the authors; licensee Growing Science, Canada. This is an open access article distributed under the terms and conditions of the Creative Commons Attribution (CC-BY) license (http://creativecommons.org/licenses/by/4.0/). 